\title{
Effect of the size of the pupae, adult diet, oviposition substrate and adult population density on egg production in Musca domestica (Diptera: Muscidae)
}

\author{
Berta PASTOR ${ }^{1}$, Helena ČIČKOVÁ², Milan KOZÁNEK²*, Anabel MARTíNEZ-SÁNCHEZ ${ }^{1}$, Peter TAKÁČ² \\ and SANTOS ROJO ${ }^{1}$
}

\begin{abstract}
${ }^{1}$ Departamento de Ciencias Ambientales y Recursos Naturales / Instituto Universitario CIBIO, Universidad de Alicante, P.O. Box 99, E-03080 Alicante, Spain; e-mails: berta.pastor@ua.es; anabel.martinez@ua.es; santos.rojo@ua.es

${ }^{2}$ Institute of Zoology, Slovak Academy of Sciences, Dúbravská cesta 9, 84506 Bratislava, Slovakia; e-mails: helena.cickova@savba.sk; milan.kozanek@savba.sk; peter.takac@savba.sk
\end{abstract}

Key words. Diptera, Muscidae, Musca domestica, housefly, fecundity, size of the pupae, protein supplements, substrate presentation, substrate quality, spatial requirements, size of flies, mass rearing

\begin{abstract}
In order to enhance the mass production of the house fly, Musca domestica, five aspects of its oviposition biology were analyzed. Oviposition substrate and the manner of its presentation, the composition of the diet of the adults, size of the pupae and numbers of flies in a cage were identified as critical. Females preferred to lay eggs on a substrate which was presented within a shelter and with increased linear edges against which the flies could oviposit. Different types of oviposition substrate resulted in comparable yields of eggs. The presence of an oviposition attractant (ammonia) in the manure was found to have a potentially positive effect on female fecundity. Egg yield increased when two protein sources (yeast and milk) were included in the adult diet. However, flies fed a mixture of sugar and yeast laid over 50\% fewer eggs than those fed the same proportion of sugar and milk. The fecundity of flies decreased with increase in the number of flies per cage, but the highest total number of eggs per cage was obtained when the flies were most crowded $\left(14.2 \mathrm{~cm}^{3}\right.$ per fly). The size of the pupae did not significantly affect egg production.
\end{abstract}

\section{INTRODUCTION}

Pork production is an important sector in the economy of many countries in the European Union. However, pig farming has also traditionally resulted in the production of large quantites of manure, the disposal of which is currently a major problem (Estellés et al., 2008). This is further exacerbated as pig farming tends to be concentrated in areas where the production of manure exceeds the fertilizer requirements of the environment.

It is known that some fly species, such as Hermetia illucens (Linnaeus, 1758) (Diptera: Stratiomyidae) (Sheppard et al., 1994) and in particular Musca domestica Linnaeus, 1758 (Diptera: Muscidae) can be used to degrade livestock waste (Calvert et al., 1970; Beard \& Sands, 1973; Golubeva \& Erofeeva, 1982; Barnard et al., 1998). However, for this it is necessary to continually produce large numbers of eggs to provide the larvae needed to process voluminous quantities of manure. For example, El Boushy (1991) reports that a medium-sized poultry farm, with 25,000 hens, produces $17,500 \mathrm{~kg}$ of wet manure per week and that $0.75 \mathrm{ml}$ of house fly eggs is required to decompose $1 \mathrm{~kg}$ of fresh poultry manure. Hence, to process the total amount of manure produced by a 25,000 hens per week, approximately 13 litres of eggs are needed. Although $M$. domestica is well studied and there are standard laboratory techniques for rearing it (Singh \& Moore, 1985), currently there are no methods for rearing it on an industrial scale. Previous studies concentrated mainly on the rearing and development of larvae (Hogsette, 1992; Barnard et al., 1998) and there are only a few small-scale laboratory studies on the rearing of adults (see e.g., Shipp \& Osborn, 1967; Zhemchuzhina \& Zvereva, 1985; Zvereva \& Zhemchuzhina, 1988), some of which determined only potential (and not actual) female fecundity.

According to Zvereva \& Zhemchuzhina (1988), the most critical factors affecting the number of eggs a female can oviposit, include environmental temperature, quantity and quality of larval diet, quantity and quality of adult diet, mating, adult population density, age of flies, oviposition substrate, photoperiod and genetic factors. Some of these factors and their effects on female fecundity have been determined to various degrees for many insect species.

Several authors (Zvereva \& Zhemchuzhina, 1985; Hogsette \& Washington, 1995; Ward et al., 1999) report that female flies can be very choosy about where they oviposit with marked preferences for particular substrates. The oviposition sites selected are frequently those that are most favourable for larval development (Ward et al., 1999). Availability of suitable oviposition sites can in turn affect the fecundity of the flies. Female house flies presented with oviposition substrates that lack important taste or olfactory stimuli lay very few eggs (Zvereva \& Zhemchuzhina, 1988). House flies and other insects need a balanced diet consisting of both sugar and protein in order to successfully mature their reproductive system

\footnotetext{
* Corresponding author; e-mail: milan.kozanek@savba.sk
} 
and produce eggs (Glaser, 1927; Adams \& Nelson, 1990). High population density, a typical feature of mass-rearing, negatively influences fecundity in many insects both directly during adult life (see e.g. Ohnisni, 1976; Wardhaugh \& Didham, 2005; Hari et al., 2008) and indirectly during the larval stage when it results in not only high larval mortality but also small adults, which have a low reproductive potential (Black \& Krafsur, 1987; Honěk, 1993).

Many of these results come from field or small-scale laboratory studies. In a mass-rearing system, however, high numbers of flies are needed to produce the volume of eggs required. Under such conditions, mutual interactions among the flies are likely to occur more often (Louw, 1964). This can have a detrimental effect on insect reproduction and may also alter the effects of other factors on fecundity. Thus, their influence may become negligible or more important than under field or standard laboratory rearing conditions. For example, mass propagation of the bug Rhodnius prolixus Stål, 1859 (Hemiptera: Reduviidae) revealed that at very high population densities the access of these insects to food is limited and oviposition decreases (Gómez-Núńez, 1964). The food restriction can also obscure the effect of adult size on fecundity (Jann \& Ward, 1999). Therefore, in order to develop an effective technique for producing large numbers of insects, factors previously shown to influence fecundity should be reassessed and the selection of traits or procedures that have no positive effect on insect reproduction under these conditions avoided.

Previous research has shown that different sources of dietary protein can have different effects on longevity and fecundity, and some sources are more suitable than others (Turner \& Hair, 1967). The traditional protein source for adult house flies used in laboratory studies is milk powder, which is relatively expensive. Adult blow flies and house flies can produce eggs when supplied with yeast products, which is a more cost-effective source of protein (Harlow, 1956; Shipp \& Osborn, 1967), and could replace milk powder without any appreciable loss in egg production or effect on their viability and ageing. We also assume that different oviposition substrates can influence the fecundity of the flies and hatchability of the eggs, as suggested by Beard \& Sands (1973). Since different media provide the flies with different taste and olfactory stimuli, it is possible that they will also stimulate oviposition to different degrees. The addition of an oviposition attractant (ammonia) may also increase the number of eggs laid. Additional features of the oviposition medium, such as suitable areas for oviposition and a shelter over the oviposition substrate could simulate naturally preferred oviposition sites (dark, moist areas). We hypothesize that such surface modifications could increase the attractiveness of an oviposition site, provide protection for ovipositing flies and reduce the incidence of random ovipositions. In accordance with previous research it is likely that high adult population density negatively affects insect fecundity. However, it is possible that flies maintained at high population densities produce a higher total number of eggs than flies kept at low population densities. If the effect of adult population density is so strong that the total number of eggs collected from cages containing high numbers of flies is less than that in cages with low numbers of the flies then rearing flies at high population densities is ineffective. Should the opposite be true, then fewer cages of flies would be required to produce the required number of eggs, which decreases the cost of production. Finally, the effect of body size on egg production should be evaluated. It is known that under certain conditions, e.g. nutritional stress, big adults can be at a disadvantage, perhaps due to the higher maintenance costs of a larger body (Jann \& Ward, 1999). It is likely that mass-rearing conditions constitute a form of stress, which could negatively affect the performance and reproduction of the biggest adults.

The aim of this study is to evaluate the effect of quality and presentation of the oviposition substrate, adult diet and age of flies, adult population density, and adult size on egg production by house flies under mass-rearing conditions. An understanding of these factors would allow us to define the conditions under which house fly adults should be maintained in order to increase the effectiveness of the rearing process.

\section{MATERIAL AND METHODS}

The $M$. domestica used in the experiments were obtained from a colony, which was reared at a pig manure degrading pilot plant at Miloslavov, Slovakia. The initial house fly colony (several thousands of adult flies) was established at the biodegradation facility in 2005 from pupae provided by the Institute of Animal Biochemistry and Genetics, SAS and which was gradually mixed with wild house flies (about 500 individuals per year) that emerged from pupae found in pig manure at the farm in Miloslavov. The colony was propagated and maintained at between 750,000 and 1,000,000 individuals, of which about $30,000-40,000$ were actively reproducing adult flies.

Flies used in the experiments were obtained by rearing the larvae in pig manure at a low population density $(1.5 \mathrm{ml}$ eggs per $5 \mathrm{~kg}$ of manure) in order to obtain high quality pupae (18-20 $\mathrm{mg}$ ). Once larvae pupated, the pupae were separated from the manure by flotation. Adults were kept at a constant temperature, humidity and photoperiod $\left(25 \pm 2^{\circ} \mathrm{C}, 50-70 \% \mathrm{RH}, 12 \mathrm{~L}: 12 \mathrm{D}\right)$ in experimental cages $(30 \times 30 \times 30 \mathrm{~cm})$ and provided with water and food ad libitum. The number of pupae placed in a cage depended on the experiment.

\section{Presentation of the oviposition substrate}

The oviposition substrate was presented in four different ways. These were: a control consisting of just the oviposition substrate, oviposition substrate with linear edges, oviposition substrate within a shelter and a combination of the previous two treatments. In each case the oviposition substrate was a mixture of $100 \mathrm{~g}$ of pig manure, $30 \mathrm{~g}$ of yeast and $100 \mathrm{ml}$ of water. In the control treatment, the substrate alone was offered in Petridishes. In the oviposition substrate with linear edges treatment a cross made of black paper was placed on the substrate in the middle of each Petri-dish to provide support area for oviposition. In the oviposition substrate with shelter treatment, a lid of black paper with lateral apertures through which the flies could enter was placed over the substrate in each Petri-dish. The combined oviposition substrate treatment was a combination of the previous two modifications. Four dishes containing the different 
treatments were offered daily at randomly located positions in each of ten cages. Every cage contained the adults that emerged from five hundred pupae. This experiment ran for ten days from the time the first egg was observed on the oviposition substrate and then the number of eggs laid each day and accumulated weight of eggs were compared. The weight of the eggs was measured $(1 \mathrm{~g} \approx 9,119$ eggs $)$.

\section{Quality of the oviposition substrate}

Four oviposition substrates were tested: (1) pig manure (control), (2) pig manure with $1 \mathrm{ml}$ of $8 \%$ ammonia solution, (3) dry dog food mixed with a $0.9 \%$ yeast suspension (in ratio of 5:6) and (4) rolled oats mixed with powdered milk and water (in a ratio of 12:4:9). Two thousand pupae were placed in each cage and the adult flies were fed sugar and powdered milk (in a ratio of 1:1). Each oviposition substrate was offered in a special device. For this, $50 \mathrm{ml}$ of the oviposition medium were placed in the centre of a black cloth $(20 \times 20 \mathrm{~cm})$ and formed into a "bag", which was closed with a rubber band. The bag was placed on top of a $200 \mathrm{ml}$ container that contained about $50 \mathrm{ml}$ of water. A sponge strip, which served as a wick, passed through an aperture in the lid of the container. The bag containing the medium was placed on the sponge wick, which served to keep the medium moist. A bigger cup with two longitudinal openings at the bottom (ca. $1 \times 2-3 \mathrm{~cm}$ ) was placed over this structure as a shelter. When placed in the cages, the flies entered the device through the openings in the upper cup and laid eggs on the cloth bag. The eggs were then easily washed off the cloth. Each cage contained a single oviposition device and eggs were collected over a period of fifteen days starting six days after adult emergence. The flies were allowed to oviposit for $12 \mathrm{~h}$. Eight replicates were conducted for each treatment except for the rolled oats with milk and water oviposition substrate, for which there were only seven replicates. The number of eggs laid per female was estimated volumetrically $(1 \mathrm{ml} \approx$ 11,000 eggs). Thirty samples of eggs per treatment were taken on four consecutive days, to check for differences in the hatchability of the eggs laid on the different substrates.

\section{Adult diet and age of flies}

Four adult diets were tested: sugar with powdered milk (2:1), sugar with dried yeast $(2: 1)$, sugar with powdered milk and yeast $(2: 1: 1)$ and sugar alone as a control. All diets were dispensed ad libitum. Each diet was placed in a cage with five hundred pupae and each diet was replicated five times. The weight and hatchability of the eggs laid each day were measured for each diet over a period of thirty-four days. This period was considered sufficient to reveal whether senescence of flies affects the volume and quality of the eggs produced as reported in previous studies (Rockstein, 1957). The percentage of eggs that hatched 24, 48 and $72 \mathrm{~h}$ after oviposition was recorded in order to determine whether adult diet affected the developmental time of the eggs. This procedure was followed for the first five days and replicated five times for each treatment.

\section{Adult population density}

Four different numbers of pupae (500, 1000, 1500 and 2000) were placed inside the experimental cages and the flies fed with sugar and powdered milk (at a ratio of 1:1). The number of pupae in the "high" population density treatment was the highest number of flies that could be kept in a cage without risk of a massive escape of flies during routine manipulations (e.g., inserting/removing the oviposition device). Hence, the space available per fly was $56.8,28.4,18.9$ and $14.2 \mathrm{~cm}^{3}$, respectively. All densities were replicated eight times. The oviposition substrate (pig manure) in the special oviposition device, as described above, was offered daily. Eggs were collected for fif- teen days starting six days after adult emergence. The volume of eggs deposited was measured $(1 \mathrm{ml} \approx 11,000$ eggs $)$ and the mean numbers of eggs laid per female estimated.

\section{Adult size}

Pupae of different mean weights (9.50-21.32 mg) were obtained by rearing different numbers of larvae in the same quantity of pig manure $(0.25$ to $1.1 \mathrm{ml}$ of eggs per $1 \mathrm{~kg}$ of pig manure). The size of the pupae was characterized by weighing individually fifty pupae from each larval treatment two days before the expected emergence of adults. Two thousand pupae of four size categories $(<12 \mathrm{mg}, 12-16 \mathrm{mg}, 16-20 \mathrm{mg}$ and $>20$ $\mathrm{mg}$ ) were placed inside each experimental cage and the flies were fed with sugar and powdered milk (in a ratio of 1:1). The percentage of pupae that emerged to adults was determined for each cage. The oviposition substrates (pig manure) in clothwrapped bags, as described above, were offered every day for fifteen consecutive days starting on the sixth day after emergence. The volume of eggs collected daily and the numbers of eggs laid per female were estimated.

\section{Data analysis and statistical procedures}

In all the experiments 200 pupae from the same breeding stock as the experimental flies was kept in the same rearing room as the experimental cages in order to determine the number of eggs produced per female in every experiment. The percentage of the pupae that produced adults and their sex ratio was recorded and these values were used in the analysis of the experimental results. To determine the percentage of eggs that hatched, a minimum of 100 eggs was placed in a Petri-dish (5.5 $\mathrm{cm} \times 1.5 \mathrm{~cm})$ on filter paper with a sponge soaked in water to prevent dehydration.

Results of each experiment were checked for normality using the Kolmogorov-Smirnov test and for heteroscedascity using Bartlett's test. Total weights (accumulated) of eggs laid in the substrate presentation experiment were analysed and compared using Friedman's test followed by the modified Dunn test. Total numbers of eggs as well as numbers of eggs laid per female on different types of oviposition substrate were subjected to one-way ANOVA and significantly different means were separated by post-hoc Tukey's (HSD) test. Kruskal-Wallis test followed by Dunn test were employed to determine significant differences in the percentages of the eggs laid on the different types of oviposition substrate that hatched. The effect of adult diet on daily and total egg weights was determined using a one-way ANOVA followed by Tukey's test. Overall percentage of eggs that hatched in the different diet treatments were analysed using the Kruskal-Wallis test and significantly different means separated using the Dunn test. Differences in the percentage of eggs that hatched in the different diet treatments on individual days were examined using one-way ANOVA followed by Tukey's test. Differences in time taken for the eggs to hatch among different adult diet treatments were analysed using Friedman's test. Finally, the total number and number of eggs laid by each female in the different adult population density and adult size treatments were assessed using one-way ANOVA followed by Turkey's test. All data were analyzed using the SPSS statistical package.

\section{RESULTS}

\section{Presentation and quality of the oviposition substrate}

There were significant differences in the accumulative weights of eggs laid in the different substrate presentation treatments $\left(\chi_{\mathrm{f}}^{2}=26.04, \mathrm{df}=3, \mathrm{P}<0.001\right)$ (Table 1). The number of eggs collected was significantly greater in the 


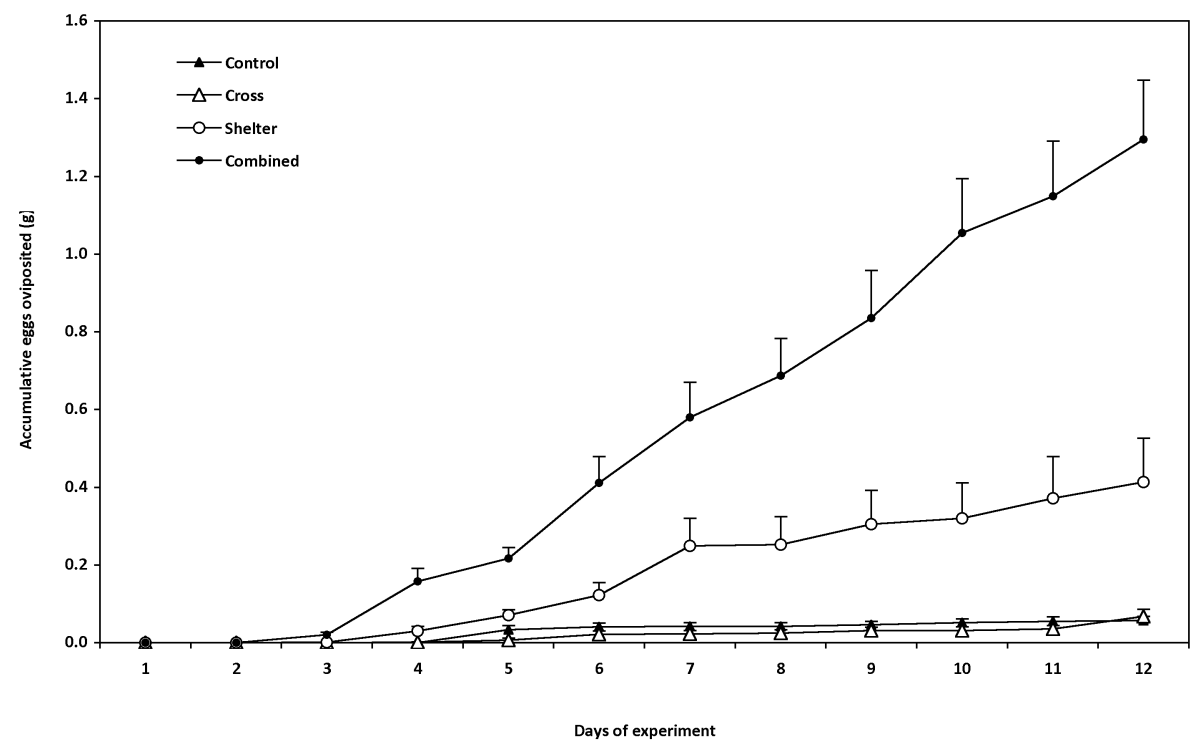

Fig. 1. Increase in total mass of eggs (g; mean $\pm 1 \mathrm{SE}$ ) laid by Musca domestica over time in each of the substrate presentation treatments.

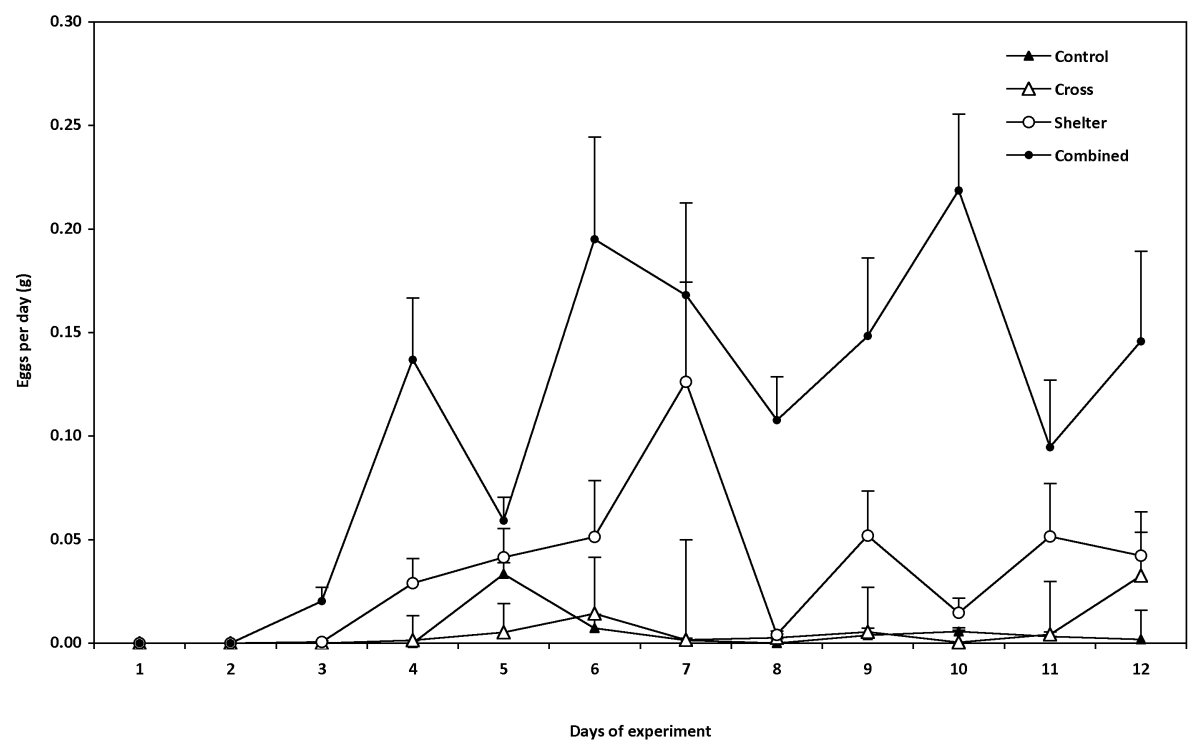

Fig. 2. Mean daily mass (g; mean $\pm 1 \mathrm{SE}$ ) of eggs of Musca domestica laid in each of the substrate presentation treatments.

TABLE 1. Total weights of eggs (mean $\pm \mathrm{SE}$ ) of Musca domestica laid in each of the substrate presentation treatments. Means followed by the same letters are not significantly different $(\mathrm{P}<$ $0.05)$.

\begin{tabular}{cc}
\hline $\begin{array}{c}\text { Substrate presentation } \\
\text { for oviposition }\end{array}$ & $\begin{array}{c}\text { Mean accumulated weight } \\
\text { of eggs laid in } 10 \text { days }(\mathrm{g})\end{array}$ \\
\hline Control & $0.057 \pm 0.011^{\mathrm{a}}$ \\
Linear edges & $0.068 \pm 0.017^{\mathrm{a}}$ \\
Shelter & $0.413 \pm 0.113^{\mathrm{b}}$ \\
Combined & $1.295 \pm 0.152^{\mathrm{c}}$ \\
\hline
\end{tabular}

combined, followed by the shelter treatment. The numbers of eggs laid in the combined treatment was twenty times greater than in the control and other treatments (Fig. 1). In terms of the numbers of eggs laid per day in each treatment it was observed to fluctuate with a maximum periodicity of three days (Fig. 2).

There were significant differences in the mean total numbers of eggs laid on each type of oviposition substrate $(\mathrm{F}=7.33$, df $=3,27, \mathrm{P}<0.005)$ (Table 2). The

TABLE 2. Total number of eggs per cage, mean number of eggs per female and mean hatchability of eggs laid on each of the four oviposition substrates (mean $\pm \mathrm{SE}$ ). Means in columns followed by the same letters are not significantly different $(\mathrm{P}<0.05)$.

\begin{tabular}{cccc}
\hline Oviposition substrate & Total number of eggs & Number of eggs per female & Hatchability of eggs (\%) \\
\hline Pig manure and ammonia & $250.413 \pm 12.123^{\mathrm{a}}$ & $273.675 \pm 13.250^{\mathrm{c}}$ & $93.909 \pm 0.785^{\text {ef }}$ \\
Pig manure & $217.781 \pm 15.083^{\mathrm{ab}}$ & $238.012 \pm 16.485^{\mathrm{cd}}$ & $94.679 \pm 0.452^{\text {ef }}$ \\
Dry dog food and yeast suspension & $180.909 \pm 6.176^{\mathrm{b}}$ & $197.715 \pm 6.750^{\mathrm{d}}$ & $94.902 \pm 0.498^{\mathrm{e}}$ \\
Rolled oats, powdered milk and water & $192.543 \pm 10.254^{\mathrm{b}}$ & $210.429 \pm 11.207^{\mathrm{d}}$ & $93.097 \pm 0.544^{\mathrm{f}}$ \\
\hline
\end{tabular}



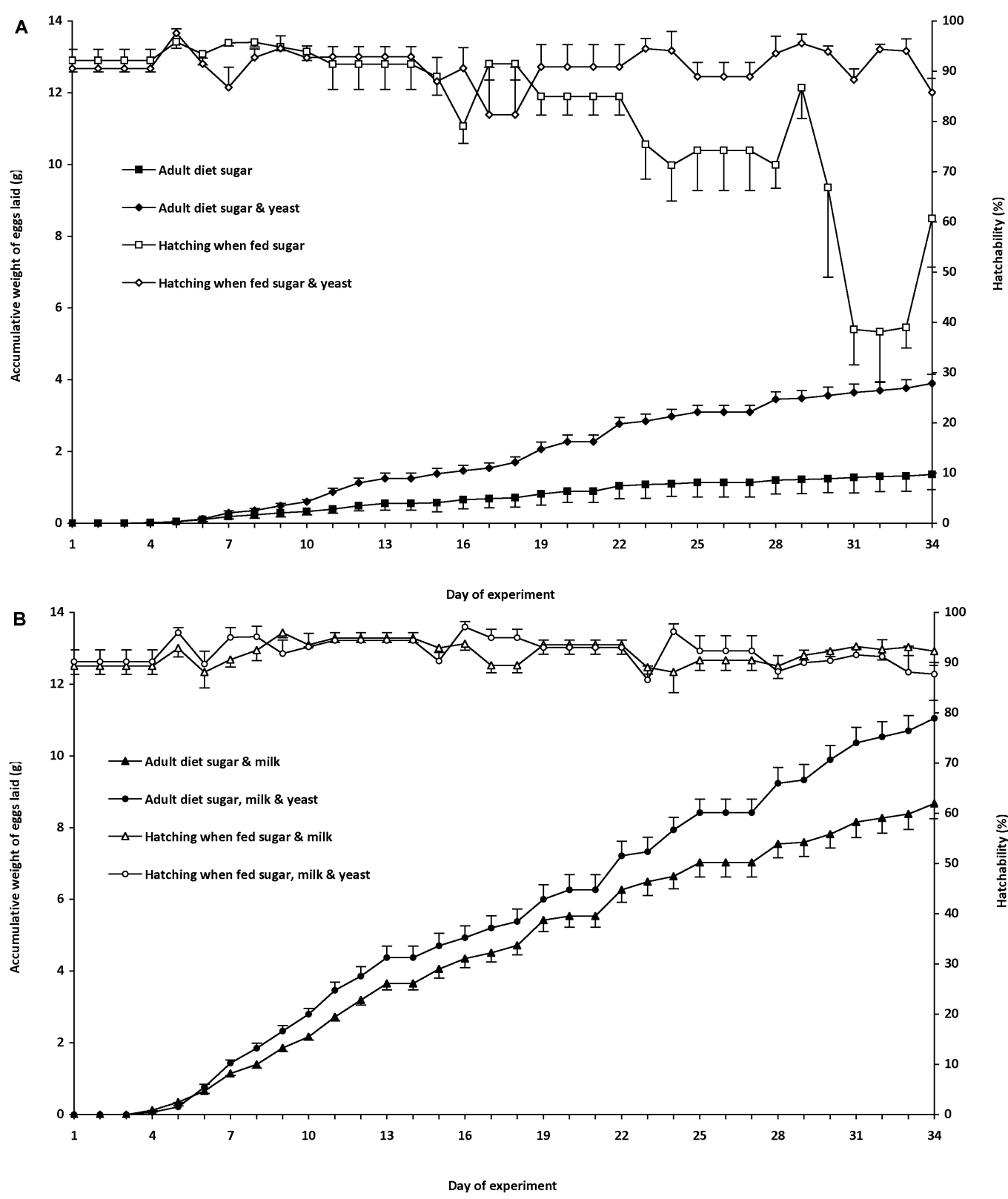

Fig. 3. Increase in total mass of eggs ( $\mathrm{g}$; mean $\pm 1 \mathrm{SE}$ ) laid by Musca domestica and percentage of the eggs that hatched after $24 \mathrm{~h}$ in the different adult diet treatments over a period of 34 days. A - adult diets of sugar, and sugar and yeast; B - adult diets of sugar and milk, and sugar, milk and yeast.

number of eggs laid on the pig manure ammonia substrate was significantly higher than on the dry dog food and yeast suspension and rolled oats, powdered milk and water substrates. However, there were no significant differences in the numbers laid on pig manure and nonmanure media. The mean percentage of eggs that hatched was significantly higher of those laid on the dry dog food and yeast suspension than on the rolled oats, powdered milk and water substrate $(\mathrm{H}=8.20, \mathrm{df}=3, \mathrm{P}<0.05)$, and there were no significant differences in the percentage hatchability of the eggs laid on the other types of substrates (Table 2).

\section{Adult diet and age of flies}

Daily egg weights significantly increased when a protein source was added to the adult diet $(\mathrm{F}=91.83, \mathrm{df}=3$,
456, $\mathrm{P}<0.001$ ) (Fig. 3A, B). Differences among the four different diets were also observed when comparing accumulated weights of eggs laid over a period of thirty-four days $(\mathrm{F}=156.55, \mathrm{df}=3,16, \mathrm{P}<0.001)$. Of the diets the mixture of sugar, milk and yeast was the best in terms of the numbers of eggs produced (Fig. 3B). Over the period of 34 days the flies fed on the diet containing sugar, milk and yeast produced 100,788 eggs compared with just 12,424 eggs produced by the flies fed on sugar alone. The number of eggs laid by those flies fed the control diet was the lowest (Fig. 3A). The number of eggs laid by the flies fed sugar and yeast was higher than in the control (Fig. $3 \mathrm{~A})$. There were clear differences in the numbers of eggs laid when fed sugar and yeast and the other two diets (sugar with milk, and sugar with milk and yeast) after day six. 
TABLE 3. Total number of eggs and number of eggs laid per female over 15 days (mean \pm SE) depending on the number of flies (pupae) in the cages. Means in columns followed by the same letters are not significantly different $(\mathrm{P}<0.05)$.

\begin{tabular}{cccc}
\hline Number of pupae per cage & Space available per fly $\left(\mathrm{cm}^{3}\right)$ & Total number of eggs & Eggs per female \\
\hline 500 & 56.8 & $105.728 \pm 14.669^{\mathrm{a}}$ & $446.644 \pm 62.380^{\mathrm{d}}$ \\
1000 & 28.4 & $154.172 \pm 19.542^{\mathrm{ab}}$ & $324.006 \pm 43.052^{\mathrm{de}}$ \\
1500 & 18.9 & $211.188 \pm 22.657^{\mathrm{bc}}$ & $290.011 \pm 35.016^{\mathrm{de}}$ \\
2000 & 14.2 & $249.334 \pm 27.936^{\mathrm{c}}$ & $263.688 \pm 28.697^{\mathrm{e}}$ \\
\hline
\end{tabular}

TABLE 4. Volume of eggs and number of eggs laid per female (mean $\pm \mathrm{SE}$ ) of the females that emerged from pupae of four different weight categories. Means in columns followed by the same letters are not significantly different $(\mathrm{P}<0.05)$.

\begin{tabular}{ccccc}
\hline Weight of pupae & Average weight of pupae & Volume of eggs (ml) & Number of eggs per female & Replicates \\
\hline$<12 \mathrm{mg}$ & $10.523 \pm 0.159$ & $26.658 \pm 2.651^{\mathrm{a}}$ & $324.70 \pm 33.86^{\mathrm{b}}$ & 6 \\
$12-16 \mathrm{mg}$ & $13.530 \pm 0.139$ & $28.988 \pm 1.571^{\mathrm{a}}$ & $350.53 \pm 20.66^{\mathrm{b}}$ & 8 \\
$16-20 \mathrm{mg}$ & $17.951 \pm 0.208$ & $30.400 \pm 1.171^{\mathrm{a}}$ & $356.17 \pm 14.31^{\mathrm{b}}$ & 4 \\
$>20 \mathrm{mg}$ & $20.840 \pm 0.315$ & $30.600 \pm 1.100^{\mathrm{a}}$ & $381.44 \pm 13.71^{\mathrm{b}}$ & 2 \\
\hline
\end{tabular}

The percentage of eggs that hatched in the first $24 \mathrm{~h}$ was higher than $90 \%$ when the adults were fed all the diets (Figs 3A, B) except the sugar diet $(\mathrm{H}=38.01$, df $=$ $3, \mathrm{P}<0.001$ ) (Fig 3A). After day 19 and until the end of the experiments, the percentage that hatched was lower when the adults were fed the sugar diet than the other diets $(\mathrm{F}=49.07, \mathrm{df}=3,16, \mathrm{P}<0.001)$. Moreover, after 48 and $72 \mathrm{~h}$ the percentage hatching was similar for all the diets tested and there were no differences $(\mathrm{P}>0.05)$ in the time to hatching. Thus, adult diet is important in determining the quality of the eggs laid by old flies.

\section{Population density and size of the adults}

The population density of adult flies had a significant effect on the mean total numbers of eggs $(\mathrm{F}=8.44$, $\mathrm{df}=$ $3,28, \mathrm{P}<0.001)$ and the mean numbers of eggs laid per female $(\mathrm{F}=3.36$, $\mathrm{df}=3,28, \mathrm{P}<0.05)$. The highest mean number of eggs laid per female was recorded in the cage in which there were 500 pupae, which produced 475 flies $\left(56.8 \mathrm{~cm}^{3} / \mathrm{fly}\right)$, but the highest mean number of eggs produced was recorded in the cages with 2000 pupae (1900 flies and $14.2 \mathrm{~cm}^{3} /$ fly) (Table 3 ).

There were no significant differences in the mean volume of eggs laid and the mean number of eggs laid per female that emerged from the four mean pupal weight categories evaluated $(\mathrm{F}=0.644, \mathrm{df}=3,16, \mathrm{P}>0.05$, and $\mathrm{F}=0.505, \mathrm{df}=3,16, \mathrm{P}>0.05$, respectively). However, the numbers of eggs laid by females that emerged from large pupae were higher than laid by those that emerged from small pupae (Table 4).

\section{DISCUSSION AND CONCLUSIONS}

Optimizing the conditions for producing eggs is important for the mass-rearing of any insect species. Females need to be provided with an oviposition substrate that provides both optimal nutritional and structural conditions for the development of offspring. Moreover, ovipositing females of many species prefer sites where they are unlikely to be disturbed when laying their eggs.

Previous studies indicate that the manner in which the oviposition substrate is presented can affect the number of eggs laid (Zvereva \& Zhemchuzhina, 1988). The principal factors affecting $M$. domestica females when choosing a place for oviposition are the moisture content of the substrate, shading and its surface structure (Zhemchuzhina \& Zvereva, 1985). Additionally, the flies must be able to smell and taste the substrate (Zvereva \& Zhemchuzhina, 1988). We observed that females more commonly deposited their eggs in cracks and crevices in the substrate and that linear edges in the centre of the oviposition substrate were used as additional oviposition sites. A preference for certain surface structures is also recorded in the yellow dung fly, Scathophaga stercoraria (Linnaeus, 1758) (Diptera: Scathophagidae). These flies prefer to lay their eggs on small mounds on the surface of a dung, possibly to protect their offspring from unfavourable environmental conditions, such as flooding or dessication (Ward et al., 1999). The black dump flies Hydrotaea aenescens (Wiedemann, 1830) (Diptera: Muscidae) strongly prefer to lay their eggs on a shaded substrate (Hogsette \& Washington, 1995). Nevertheless, the most successful treatment, in terms of egg production, was that in which the oviposition container had both a crossshaped septum and was shaded, in which $71 \%$ of all the eggs collected were deposited. The oviposition device reported here provides a highly attractive substrate in terms of shelter and sites for oviposition, and allows easy and precise collection and quantification of the eggs laid in the different experiments. A similar device, but without a water supply and with a central opening in the upper cup was successfully used to collect eggs laid by black dump flies (Hogsette \& Washington, 1995).

Flies ovipositing on substrates, with and without the attractant (ammonia), had similar fecundities. This indicates that various substrates are equally suitable for collecting eggs both in the laboratory and mass-rearing facilities, especially if the use of manure is unacceptable or inconvenient. The number of eggs laid by females was higher if an attractant (ammonia) was added to the oviposition substrate. This effect was not significant if the same type of substrate was used (i.e., manure with or without ammonia), but is significant when manure + ammonia was compared with non-manure media (dry dog food moistened with yeast suspension or rolled oats with milk and water). Several authors (Zhemchuzhina \& Zvereva, 1985; J.A. Hogsette, pers. comm.) report that ammonia 
(which is naturally present in small amounts in manure mixed with urine) is very attractive to ovipositing houseflies. However, the addition of ammonia cannot account for the statistical difference in the fecundity of the flies because the number of eggs laid on manure without ammonia was not significantly different from the numbers laid on the other "ammonia-free" substrates. It is likely that manure contains a complex of substances that are attractive for flies and could potentially induce them to lay more eggs. In the presence of ammonia the effect of other substances in manure could be enhanced and result in a higher number of follicles developing in the ovaries and a higher number of eggs laid. This experiment also showed that adding a small amount of ammonia to an oviposition substrate does not negatively affect the viability of the eggs or the viability and fitness of the flies. As previously reported (Beard \& Sands, 1973) we also expected the flies to lay a higher number of eggs on the dry dog food substrate. Differences between our results could be due to the different way in which the medium was offered and to a lesser degree in differences in the composition of the dry dog food and manure. As the medium was wrapped in a cloth bag and dog meal granules retain their shape and absorb water, it only provided a few gustatory stimuli for the flies. In the case of the manure and the rolled oats with milk and water medium, a small amount of fluid from the medium always seeped through the cloth, which provided the flies with more gustatory information. Rolled oats with milk and water medium seemed to be less suitable for oviposition, because it dried out quickly, but this could be overcome by reducing the time for oviposition to, e.g., $8 \mathrm{~h}$ or less. Drying out of the medium was probably the cause of the significantly lower percentage of eggs that hatched in this treatment.

The addition of a protein supplement to the diet of adult house flies results in an increase in egg production. Glaser (1923) reports zero egg yield when house flies are fed only sucrose. The same occurs in the face fly, Musca autumnalis De Geer, 1776 (Diptera: Muscidae) and blowfly Protophormia terraenovae (Robineau-Desvoidy, 1830) (Diptera: Calliphoridae) (Harlow, 1956; Turner \& Hair, 1967). However, feeding flies protein and no sucrose results in a dramatically reduced lifespan and no eggs being laid (Glaser, 1923; Harlow, 1956; Turner \& Hair, 1967). Detailed observations on the blowfly, Calliphora vicina Robineau-Desvoidy 1830 (Diptera: Calliphoridae) (Strangways-Dixon, 1961) show that it needs both sugar and proteins for producing eggs and that the ratio of sugar to protein ingested changes with the stage of egg development. The same is probably true for $M$. domestica. Thus, a well-balanced diet is necessary for successful reproduction. Comparison of the non-protein diet (control) with diets enriched with protein supplements revealed that the addition of protein to the diet resulted in a substantial increase in egg production. The non-zero egg production recorded for the flies fed only sugar is probably the result of the flies feeding on manure (oviposition substrate), which can support the development of eggs to a certain degree (Beard \& Sands, 1973).
Compared to the sugar diet, the volume of eggs produced was eight times greater when fed the diet enriched with a mixture of milk and yeast, six times greater when fed the milk diet and three times greater when fed the yeast diet. The yeast diet was not as suitable as reported by Shipp \& Osborn (1967) who found that the best diet for adult houseflies was a mixture of yeast (Kraylift) and sugar in the ratio of $3: 1$. Flies fed a $75 \%$ yeast diet laid on average 286 eggs per female in 14-15 days, compared to only 90 eggs per female when fed powdered skimmed milk. In our experiment, flies fed a mixture of sugar and milk laid on average twice as many eggs as those fed sugar and yeast over a period of 30 days. Several factors may account for the discrepancy between our results and those of Shipp \& Osborn (1967): differences in the strains of flies and rearing techniques, and the quality of the yeast and powdered milk used. Additionally, these authors report different numbers of flies in the experimental cages, which could also have influenced their results. Since differences in egg yield were obvious from the sixth day of egg collection onwards, the longer egg collection period used in this study probably did not affect the result, although it probably resulted in a clearer difference in egg production.

In a mass production system, using the adult diet that resulted in the poorest egg production (sugar), cages of 40,000 adults would produce a total of $65.8 \mathrm{ml}$ of eggs per cage over a period of two weeks. However, when the flies were fed a diet enriched with milk and yeast, 526.5 $\mathrm{ml}$ of eggs would be produced in two weeks. Thus, $88 \mathrm{~kg}$ of poultry manure could be degraded by larvae produced from the volume of eggs obtained when flies are fed a sugar diet. But by adding milk and yeast to the diet, $\approx 700$ $\mathrm{kg}$ of poultry manure could be degraded by the larvae produced from the eggs obtained from only one cage of flies. The number of eggs obtained per female in our experiment, which focused on the adult fly's nutrition, was slightly higher than that reported by other authors. For example, Lysyk (1991) reports a maximum rate of oviposition in a field experiment of 11.4 eggs per female. The average number of eggs laid per day when fed the best diet was 14.2 eggs per female. Fletcher et al. (1990) report a lifetime reproductive output of 433.1 eggs at a similar temperature $\left(25^{\circ} \mathrm{C}\right)$ for flies fed diluted evaporated milk and granular sugar. Our data are comparable, because with the best diet, the total number of eggs produced was 453.22. The best period for collecting the eggs of $M$. domestica is from day 7 to day 22 after adult emergence (day 4 to day 19 after the first egg is laid). That is, the eggs should be collected over a period of two weeks and then the colonies should be replaced. The day on which the maximum number of eggs was produced is similar to that reported by Sun et al. (2002), who recorded a peak in oviposition about four days after the first egg is laid. These authors restricted egg production to a period of 3 to 5 days when the yield of eggs is at its highest in order to continuously keep the fecundity at a high level. However, our results show that the period for which egg production remains high in the housefly is much longer. 
Our study of the relationship between longevity and fertility revealed that adult house flies fed sugar were still able to lay eggs when thirty four days old. In contrast, Rockstein (1957) reports a female mortality of $99 \%$ after thirty four days when the adults were provided with milk. However, Berberian et al. (1971) and Golubeva (1984) report that the longevity of flies might be related to the number of batches of eggs or numbers of eggs laid, which in turn depends on the diet fed to the flies and availability of suitable substrates for oviposition. Our data confirm that flies should not be kept for more than thirty days because by then $50 \%$ of the females have died. Our results on the relationship between the viability of eggs and the age of the flies do not correspond with those of McIntyre \& Gooding (2000) who record a decrease in hatchability with age. Except in the control treatment (sugar diet for adult), the percentage of eggs that hatched each day was similar throughout the duration of the experiment and remained higher than $90 \%$ in the experiments in which the diets fed to the adults contained protein.

Increasing population density has a negative effect on fecundity in many insects. There is a significant decrease in egg load with increase in the population density of adult beech scale insects Ultracoelostoma assimile (Maskell, 1890) (Hemiptera: Margarodidae) in the field (Wardhaugh \& Didham, 2005). Laboratory investigations record a similar effect of high population density on reproduction in the butterfly Chilo partellus Swinhoe 1885 (Lepidoptera: Crambidae) (Hari et al., 2008) and Drosophila melanogaster Linnaeus, 1758 (Diptera: Drosophilidae) (Ohnisni, 1976). For the house fly, the effect of population density on female fecundity is reported occurring in field (Black \& Krafsur, 1987) and laboratory experiments (Zvereva \& Zhemchuzhina, 1988). However, Osborn et al. (1970) report no adverse effects of density as high as between 2.57 and 4.77 flies per cubic inch (i.e.; 6.38-3.435 $\mathrm{cm}^{3}$ per fly). In D. melanogaster, a 4-fold increase in adult density (from 2 pairs per vial to 8 pairs per vial) resulted in $26-37 \%$ decrease in female fecundity measured over a period of 20 days (Ohnisni, 1976). In our experiment, a 4-fold increase in adult density per cage (from 500 to 2000 pupae per cage, i.e. from $56.8 \mathrm{~cm}^{3}$ to $14.2 \mathrm{~cm}^{3}$ per fly) resulted in a decrease in the average number of eggs laid per female by $41 \%$, which is slightly higher than that reported for D. melanogaster (Ohnisni, 1976). This result differs from the data presented by Osborn et al. (1970), probably because the strain of fly and rearing technique used differed. For optimum egg production we recommend rearing house flies at a high density. Although it has negative effect on the fecundity of individual flies, the total yield of eggs is higher. Keeping flies at higher population densities $\left(<14.2 \mathrm{~cm}^{3}\right.$ per fly) may pose nuisance problems due to greater risk of flies escaping from the cages.

A positive correlation between potential fecundity and body size is recorded for many insects (Honěk, 1993; but see also Leather, 1988), including M. domestica (Black \& Krafsur, 1987). Large females lay more eggs than small ones due to a higher number of ovarioles and a larger abdominal space, which can house more developing eggs (Honěk, 1993). Barnard et al. (1995) conclude that a $1 \mathrm{mg}$ increase in mean housefly pupal mass results in the laying of an estimated $10.6 \pm 1.5$ additional eggs when the females are kept at low population densities. In contrast, it is also reported that under certain circumstances, such as nutritional stress, small females of Scathophaga stercoraria may lay more eggs than large females (Jann \& Ward, 1999). The factors limiting body size is an important topic in life-history research, and there is little information on the factors limiting size in insects (Blanckenhorn, 2000; Gotthard et al., 2007). Our experiment suggests that when space is limited and population densities are high, larger body size may be selected against. This effect may therefore be interesting and relevant to life-history research (although the relevance of our findings to natural conditions may be limited). For the mass rearing of house flies, medium-sized pupae are more suitable, because even though there were the same number of flies per cage, most of the adults in cages provisioned with large pupae died within 7 days of emergence. This indicates either that the adults emerging from extremely big pupae ( $>20 \mathrm{mg}$ ) were less fit or the critical space requirement of the flies was exceeded or a combination of both. The flies emerging from heavier pupae are bigger than those emerging from lighter (and smaller) pupae. Thus, despite the same number of the flies per cage, less space was available per fly in the cages that were provided with big pupae and interactions between these flies presumably occurred more frequently. Mutual interactions between flies occur more often in overcrowded populations and may result in an increase in metabolic rate due to a lack of sufficient resting sites (Louw, 1964). This is also supported by the observation that the majority $(\sim 88 \%)$ of the dead flies in cages provided with big pupae were males. It is reported that life expectancy of male house flies dramatically decreases as the population density of flies increases and the space per fly decreases, whereas the mortality of the females increases only slightly (Rockstein et al., 1981).

Oviposition in house flies is strongly influenced by several factors that determine the volume of eggs produced. The results indicate that high yields of eggs can be obtained if the flies are fed a high quality protein source (a mixture of sugar, yeasts and powdered milk in a ratio of $2: 1: 1)$ and kept at high population density $\left(14.2 \mathrm{~cm}^{3}\right.$ per fly). The best oviposition substrate was pig manure with ammonia, but other oviposition substrates can be used as they do not have any negative effects on fly fecundity and the addition of an oviposition attractant (ammonia) can slightly increase the quantity of eggs laid. The oviposition substrate should be presented in a shelter and have linear edges to help oviposition, such as in our proposed oviposition device. Selection of large rather than medium-sized flies for reproduction should be avoided since crowding large adults can result in high mortality. 
ACKNOWLEDGEMENTS. This study was funded by project LIFE-ECODIPTERA (LIFE05-ENV/E/000302) and partially by Alicante University (GRE09-27) and Generalitat Valenciana (GV/2011/039). We are very thankful to J.A. Hogsette (USDAARS, USA) and R. Wall (School of Biological Sciences, University of Bristol, England) for invaluable advice and reviewing the manuscript. Finally we are very grateful to the two anonymous reviewers of this journal for their valuable comments.

\section{REFERENCES}

Adams T.S. \& Nelson D.R. 1990: The influence of diet on ovarian maturation, mating, and pheromone production in the housefly, Musca domestica. Invertebr. Reprod. Dev. 17: 193-201.

Barnard D.R., Harms R.H. \& Sloan D.R. 1995: Influence of nitrogen, phosphorus, and calcium in poultry manure on survival, growth, and reproduction in house fly (Diptera: Muscidae). Environ. Entomol. 24: 1297-1301.

BARNARD D.R., Harms R.H. \& SloAn D.R. 1998: Biodegradation of poultry manure by house fly (Diptera: Muscidae). Environ. Entomol. 27: 600-605.

BEARD R.L. \& SANDS D.C. 1973: Factors affecting degradation of poultry manure by flies. Environ. Entomol. 2: 801-806.

Berberian P.A., RocksteIn M. \& Gray F.H. 1971: The effect of egg laying on the longevity of the adult female house fly, Musca domestica L. J. Gerontol. 26: 485-489.

Black W.C. \& Krafsur E.S. 1987: Fecundity and size in the housefly: investigations of some environmental sources and genetic correlates of variation. Med. Vet. Entomol. 1: 369-382.

BLANCKENHORN W.U. 2000: The evolution of body size: what keeps organisms small? Q. Rev. Biol. 75: 385-407.

Calvert C.C., Morgan N.O. \& Martin R.D. 1970: House fly larvae: Biodegradation of hen excreta to useful products. Poult. Sci. 49: 588-590.

El Boushy A.R. 1991: House-fly pupae as poultry manure converters for animal feed: a review. Bioresour. Technol. 38: $45-49$.

Estellés F., Gallego A., Moset V., Cambra M., Berné J.L. \& ToRres A.G. 2008: Determinación de zonas susceptibles para el aprovechamiento energético de las deyecciones ganaderas en la Comunidad Valenciana. I Congreso Espańol de Gestión Integral de Deyecciones Ganaderas. Barcelona, Spain.

Fletcher M.C., Axtell R.C. \& Stinner R.E. 1990: Longevity and fecundity of Musca domestica (Diptera: Muscidae) as a function of temperature. J. Med. Entomol. 27: 922-926.

GLASER R.W. 1923: The effect of food on longevity and reproduction in flies. J. Exp. Zool. 38: 383-412.

Golubeva E.G. 1984: Fecundity of the house fly Musca domestica L. developing on some organic wastes (under conditions of individual rearing). Medskaya Parazit. 54: 40-43 [in Russian].

Golubeva E.G. \& Erofeeva T.V. 1982: Growth dynamics of housefly larvae on organic wastes in a biological human life support system. Kosm. Biol. Aviakosm. Medit. 16: 74-76 [in Russian].

GóMEZ-NúŃEZ J.C. 1964: Mass rearing of Rhodnius prolixus. Bull. World Health Org. 31: 565-567.

Gotthard K., Berger D. \& Walters R. 2007: What keeps insects small? Time limitation during oviposition reduces the fecundity benefit of female size in a butterfly. Am. Nat. 169: 768-779.

HaRi N.S., Jindal J., Malhi N.S. \& Khosa J.K. 2008: Effect of adult nutrition and insect density on performance of spotted stem borer, Chillo partellus in laboratory cultures. J. Pest Sci. 81: $23-27$.

Harlow P.M. 1956: A study of ovarian development and its relation to adult nutrition in the blowfly Protophormia terraenovae (R.D.). J. Exp. Biol. 33: 777-797.

Hogsette J.A. 1992: New diets for production of house flies and stable flies (Diptera: Muscidae) in the laboratory. J. Econ. Entomol. 85: 2291-2294.

Hogsette J.A. \& Washington F. 1995: Quantitative mass production of Hydrotaea aenescens (Diptera: Muscidae). J. Econ. Entomol. 88: 1238-1242.

HoNĚK A. 1993: Intraspecific variation in body size and fecundity in insects: a general relationship. Oikos 66: 483-492.

JANN P. \& WARD P.I. 1999: Maternal effects and their consequences for offspring fitness in the yellow dung fly. Funct. Ecol. 13: 51-58

LEATHER S.R. 1988: Size, reproductive potential and fecundity in insects: things aren't as simple as they seem. Oikos 51: 386-389.

Louw B.K. 1964: Physical aspects of laboratory maintenance of muscoid fly colonies. Bull. World Health Org. 31: 529-533.

LYSYK T.J. 1991: Modelling oviposition of the house fly (Diptera: Muscidae). Can. Entomol. 123: 345-352.

McIntyre G.S. \& Gooding R.H. 2000: Egg size, contents and quality: maternal-age and size effects on house fly eggs. Can. J. Zool. 78: 1544-1551.

OHNISNI S. 1976: Effect of population density and temperature condition on fitness in Drosophila melanogaster. II. Fecundity and mortality. Jap. J. Genet. 51: 305-314.

Osborn A.W., Shipp E. \& Rodger J.C. 1970: House fly fecundity in relation to density. J. Econ. Entomol. 63: 1020-1021.

RocksteIN M. 1957: Longevity of male and female house flies. J. Gerontol. 12: 253-256.

Rockstein M., Chesky J.A., Levy M.H. \& Yore L. 1981: Effect of population density upon life expectancy and wing retention in the common house fly, Musca domestica L. Gerontology 27: $13-19$.

Sheppard D.C., Newton G.L., Thomson S.A. \& Savage S.E. 1994: A value added manure management system using black soldier fly. Bioresour. Technol. 50: 275-279.

Shipp E. \& Osborn A.W. 1967: The effect of protein sources and of the frequency of egg collection on egg production by the housefly (Musca domestica L.). Bull. World Health Org. 37: 331-335.

Singh P. \& MoORE R.F. (eds) 1985: Handbook of Insect Rearing. Vol. II. Elsevier, Amsterdam, 514 pp.

StrangWAYs-Dixon J. 1961: The relationship between nutrition, hormones and reproduction in the blowfly Calliphora erythrocephala (Meig.). I. Selective feeding in relation to the reproductive cycle, the corpus allatum volume and fertilization. $J$. Exp. Biol. 38: 225-235.

Sun G., Fang Y., Wang Z.T. \& Song Y.J. 2002: The effect of diet and density on the fecundity of housefly in the pilot scale production of its larvae. Acta Entomol. Sin. 45: 847-850 [in Chinese, English abstr.].

TURNER E.C. \& HAIR J.A. 1967: Effect of diet on longevity and fecundity of laboratory-reared face flies. J. Econ. Entomol. 60: $857-860$.

Ward P.I., Foglia M. \& Blanckenhorn W.U. 1999: Oviposition site choice in the yellow dung fly Scatophaga stercoraria. Ethology 105: 423-430.

Wardhaugh C.W. \& Didham K.I. 2005: Density-dependent effects on the reproductive fitness of the New Zealand beech scale insect (Ultracoelostoma assimile) across multiple spatial scales. Ecol. Entomol. 30: 733-738. 
ZhemchuZhina A.A. \& Zvereva E.L. 1985: Effect of some factors on the choice of a site for oviposition in housefly Musca domestica females. Medskaya Parazitol. 55: 55-57 [in Russian].
Zvereva E.L. \& Zhemchuzhina A.A. 1988: On some factors influencing the Musca domestica L. fecundity. Medskaya Parazitol. 58: 27-30 [in Russian].

Received November 25, 2010; revised and accepted May 26, 2011 